\title{
Uma greve em dois tempos: o movimento nacional dos marítimos de 1953 no Rio de Janeiro e os impasses da historiografia política.
}

A strike in two times: the national movement of the seafarers in Rio de Janeiro and the impasses of political historiography.

\author{
Sérgio de Sousa Montalvão** \\ Joana D’Arc Fernandes Ferraz***
}

Resumo: O objetivo deste artigo é discutir os impasses das análises historiográficas sobre a greve nacional dos marítimos de 1953, no Rio de Janeiro. Partimos da constatação que a corrente principal da historiografia política brasileira aborda este movimento como parte do processo de reconhecimento da habilidade do ministro do Trabalho João Goulart em negociar com os trabalhadores. Destacando o que seria o "estilo Jango" de administrar os conflitos trabalhistas, esta historiografia entende que o acordo firmado no mês de junho daquele ano, suspendendo a greve, seria o marco fundador do novo trabalhismo, que rompia com o corporativismo e a repressão policial do Estado Novo (1937-1945) e levava o Partido Trabalhista Brasileiro (PTB) diretamente para o campo da esquerda democrática. No entanto, o não cumprimento das cláusulas do referido acordo fez com que os marítimos cruzassem novamente os braços, em outubro de 1953. Este segundo tempo da greve é silenciado por esta corrente historiográfica, evitando assim que se mostre a polaridade entre Jango e os trabalhadores do mar. Nossa pesquisa na imprensa sindical e popular demonstra que, naquele momento, Jango ainda fundamentava sua política em muitos alicerces do velho trabalhismo.

Palavras-chave: greve dos marítimos, João Goulart, imprensa sindical e popular, historiografia política

\begin{abstract}
The aim of this paper is to discuss the impasses of historiographical analysis on national strike of seafarers of the 1953 in Rio de Janeiro. We start from the observation that the mainstream of Brazilian political historiography addresses this movement as part of the process of recognizing the ability of Labor Minister João Goulart to negotiate with workers. Highlighting what would be the "Jango style" of managing labor conflicts. this historiography understands that the agreement signed in June of that year, suspending the strike, would be the founding mark of the new labor, which broke with the corporativism
\end{abstract}

\footnotetext{
${ }^{*}$ Esta pesquisa contou com o apoio de duas bolsas de Iniciação Científica concedidas pela Fundação de Amparo à Pesquisa do Estado do Rio de Janeiro (FAPERJ). Agradecemos por este suporte institucional e pelo empenho dos bolsistas Isabelly Neves Filgueiras e Marcus Antônio Cardoso Ramalho, estudantes do curso de graduação em Administração da Universidade Federal Fluminense (UFF).

** Doutor em História, Política e Bens Culturais pelo Centro de Pesquisa e Documentação de História Contemporânea do Brasil da Fundação Getúlio Vargas do Rio de Janeiro - CPDOC/FGV-RJ. Professor Adjunto IV do Departamento de Administração e professor colaborador do Programa de Pós-Graduação em Administração da Universidade Federal Fluminense (UFF).

*** Doutora em Ciências Sociais pela Universidade do Estado do Rio de Janeiro (UERJ), professora Associada I do Departamento de Sociologia da Universidade Federal Fluminense (UFF).
} 
and the police repression of the Estado Novo (1937-1945) and took the Brazilian Labor Party (PTB) directly to the field of the democratic left. However, failure to comply with the terms of that agreement caused seafarers to cross their arms again in October 1953. This second strike time is silenced by this historiographic current, thus avoiding showing the polarity between Jango and the sea workers. Our research in the trade union and popular press shows that, at that time, Jango was still grounding his policy on the many foundations of old labor.

Keywords: Seafarers strike, João Goulart, Union and popular press, Political historiography

Recibido: 16 mayo 2019 Aceptado: 22 julio 2019

\section{Introdução}

O movimento grevista dos "trabalhadores do mar", que paralisou as atividades da marinha mercante por praticamente toda a extensão do litoral brasileiro, durante doze dias, em junho de 1953, entrou para a história das lutas sindicais da República de 1946 pelo ineditismo da organização que uniu as muitas categorias marítimas em um único comando de greve, disposto a não interromper a "medição de forças"1 com o governo e o empresariado, até ver atendidas praticamente todas as suas reivindicações. No entanto, a histórica greve de 1953, ainda tem sido majoritariamente estudada como um evento coincidente com as mudanças no primeiro escalão de governo do presidente Vargas (1951-1954), que permitiram a entrada de João Goulart, popularmente conhecido como Jango, no Ministério do Trabalho, Indústria e Comércio (MTCI).

O objetivo deste artigo é mostrar como a historiografia que privilegia a matriz do novo trabalhismo, cuja prova de fogo teria sido debelar a greve nacional dos marítimos, por meio de técnicas que evitassem o uso do aparato repressivo do Estado e oferecessem condições para negociação dos direitos trabalhistas, deixou de lado o entendimento do papel exercido pelos próprios trabalhadores na conquista desses direitos, após um período de enfrentamentos, necessário para corrigir os equívocos deixados pelo próprio Jango. Esse período esteve situado no mês de outubro de 1953, quando os marítimos cobraram o acordo anteriormente firmado com os representantes patronais, conquistando muito daquilo que ainda permanecia em aberto. O silêncio historiográfico em torno dessa questão impede que se percebam as contradições encontradas na transição do varguismo para o trabalhismo enquanto partido político organicamente vinculado ao campo das esquerdas, deixando a ilusão de uma passagem retilínea de um contexto ao outro.

A fim mostrar a forma como foi delineada a contradição entre o que a historiografia política escreve sobre este período e as fontes documentais consultadas nos jornais da imprensa sindical e popular, este artigo está desenvolvido em três partes.

Na primeira parte, é feita uma contextualização do período que antecede a entrada de João Goulart no MTIC, considerando a ascensão da luta de classes e as dificuldades para se manter as práticas de controle corporativistas dos sindicatos.

1 BARSTED, Dênis Linhares. Medição de forças: o movimento grevista de 1953 e a época dos operários navais. Rio de Janeiro: Zahar, 1981, p. 82. 
$\mathrm{Na}$ segunda parte, apresentamos a estrutura argumentativa da historiografia política sobre a renovação do trabalhismo brasileiro durante o período em tela. Ressaltamos a procura desta historiografia em mostrar o papel exercido pelo estilo Jango de negociação com os trabalhadores enquanto um marco desta renovação, exemplificando-a com os resultados alcançados pelo acordo de sustação da greve dos marítimos, assinado em junho de 1953.

$\mathrm{Na}$ terceira parte, discutimos a forma como o jornal Orla Marítima representou a figura de Jango e as querelas em torno do movimento nacional dos marítimos. Essa fonte histórica é fundamental para oferecer um contraditório à historiografia que vem se debruçando sobre esse movimento pelo ângulo do "novo trabalhismo", evidenciando a imagem de João Goulart entre os trabalhadores.

$\mathrm{Na}$ parte final, enfatizamos a singularidade da greve de outubro de 1953, quando, por meio de um forte aparato repressivo, denunciado nos periódicos da imprensa sindical e popular, fica evidente a polaridade entre Jango e os marítimos. A hipótese da articulação com os trabalhadores em um projeto nacional-reformista, utilizada como argumento central na literatura sobre o tema, é refutada neste trabalho.

\section{As greves no segundo governo Vargas e o declínio do corporativismo}

A volta de Getúlio Vargas à chefia da nação, após ter passado quinze anos na presidência da República (1930-1945), levou à composição de um governo contemporizador, disposto a reunir as principais forças político-partidárias, dentro de uma estratégia visando administrar as tensões resultantes da associação do líder trabalhista com a imagem de um perigoso controlador das massas, capaz de leválas a apoiá-lo em mais um empenho ditatorial, como havia sido o recém-encerrado período do Estado Novo (1937-1945).

Em sua nova passagem pelo poder, diante de tais circunstâncias, Vargas teria pela frente o desafio de responder às demandas dos trabalhadores que dizia representar, tanto em razão de uma pauta econômica, quanto de uma agenda mais ampla, reunindo aspectos organizativos e de interesse político, sem contrariar exageradamente os humores da classe patronal.

Em pouco tempo esse desafio sairia da caixa, manifestando-se por meio de uma quantidade cada vez maior de greves. O ano de 1951 registrou 173 movimentos paredistas, número superado no ano seguinte, quando as paralisações atingiram a marca de $264 .{ }^{2}$ Essa crescente mobilização resultou, em parte, do aperto sentido pela falta de reajuste do salário mínimo, ignorado durante todo o governo Eurico Dutra (1946-1950), mas também da necessidade de reagir às políticas antidemocráticas que atingiram os sindicatos durante a internalização da Guerra Fria no Brasil, especialmente após os comunistas terem voltado para a ilegalidade.

Completada a primeira metade do século XX, vivia-se um nítido reaquecimento da luta de classes, agora em um novo ambiente institucional, delimitado no campo jurídico por um ordenamento liberaldemocrático, embora contendo muitos dispositivos corporativistas, sobretudo para organizar o mundo do trabalho. O corporativismo, depois de orientar a guinada centralizadora do Poder Executivo na Era Vargas rumo à modernização autoritária, ainda permanecia influente, mas subordinado aos ditames da Constituição de 1946. ${ }^{3}$ A procura pela democracia social permanecia nos horizontes do varguismo, sendo esta acompanhada de uma expectativa do poder público por antecipar-se para evitar o confronto entre patrões e empregados. No entanto, o próprio desenvolvimento democrático mostrou o quanto seria difícil a tarefa.

2 TELLES, Jover. O movimento sindical no Brasil. São Paulo: LECH, 1981, p. 81.

3 STOTZ, Eduardo Navarro. Nacionalismo, intervencionismo estatal e expansão do movimento operário (1950-1955). In. Lobo, Eulália Lahmeyer (Coord.) Rio de Janeiro operário: natureza do Estado, condições de vida e consciência de classe. Rio de Janeiro: Acess Editora, 1992, p. 226. 
O ano de 1953 trouxera consigo a experiência das greves de massa, a começar pela dos 300 mil, que paralisou o setor têxtil na cidade de São Paulo. A novidade desta greve foi a negação da legislação corporativista que impedia a formação de estruturas unificadoras da ação coletiva dos trabalhadores. É então que surge o Pacto de Unidade Intersindical (PUI), permitindo a um único comando de greve responder por diversas categorias, levando-as a obter uma maior capacidade de pressão. A capacidade organizativa dos trabalhadores aumenta à medida em que a esquerda se recupera do baque sofrido pela suspensão do Partido Comunista, cujo resultado imediato foi o esvaziamento da vida sindical.

O período que antecede a arrancada das lutas de classe, no segundo governo Vargas, é marcado pela tentativa comunista de formar estruturas sindicais paralelas, em meio a uma contínua intervenção policial e ideológica por parte do Estado. No entanto, como adverte Buonicore (2000), apesar do radicalismo imposto no discurso, havia uma duplicidade na política sindical comunista. Se, por um lado, esta "não se prende ao sindicalismo oficial como única forma legítima de representação das classes trabalhadoras, por outro não propõe a supressão do sindicalismo existente por um novo e, sim, um convívio entre ambos, e, por fim, a incorporação do último pelo primeiro".4

Essa estratégia irá se manifestar com maior clareza depois de abrandada a repressão imposta por Dutra, durante a conjuntura de 1953, quando ainda não haviam sido completamente afrouxadas as correntes mais pesadas do corporativismo. Foi então que, após intensa mobilização por parte dos trabalhadores, tiveram início novas formas de diálogo com os representantes estatais, permitindo a reabilitação dos sindicatos enquanto espaço de atuação e procura de direitos. Conforme enfatiza Corrêa: "os frutos desses movimentos foram colhidos pouco tempo depois, quando grande número de trabalhadores aderiu aos sindicatos. O aumento dos operários sindicalizados veio acompanhado também de uma nova geração de sindicalistas comprometidos com o interesse da classe". ${ }^{5}$

A opção de quebrar a estrutura sindical por dentro, apoiando-se muitas vezes nos seus próprios recursos, orientou a estratégia comunista, mas não se limitou a isso. O protesto mediante a suspensão das atividades laborais entrava na conta, em definitivo, frustrando a economia simbólica do trabalhismo, embasada na "ideologia da outorga". 6 Os trabalhadores organizados apoiaram o retorno de Vargas à presidência, mas o queriam como alguém que os permitisse se expressarem.

É esse o jogo que irá se impor, daí em diante, mostrando o quanto é reducionista a tentativa de conceituar essas relações como de caráter populista. Naquilo que mais nos importa, portanto, cabe dizer que haverá um declínio do corporativismo. Embora ainda continue em ação, sedimentado institucionalmente, o corporativismo perde o brilho de antes, determinando a decadência dos seus agentes na condução das políticas trabalhistas. Esse ponto fica claro, por exemplo, ao pensarmos nas dificuldades encontradas pelo ministro Segadas Vianna, para conduzir as negociações das muitas greves que encontrara pela frente, levando-o a ser substituído por João Goulart. Este declínio é caracterizado por uma perda de valor simbólico, resultante do desinvestimento que passa a ser feito no momento em que o corporativismo deixa de ser uma alternativa concreta e sistêmica à democracia liberal e ao socialismo.

4 BUONICORE, Augusto César. Sindicalismo vermelho: a política sindical do PCB entre 1948 e 1952. Cadernos AEL, v. 7, n. 12/13, 2000, p.18. Disponível em https://www.ifch.unicamp.br/ojs/index.php/ael/article/view/2485 [Acesso em 04/04/2018].

${ }^{5}$ CORREAA, Larissa Rosa. O corporativismo dos trabalhadores: leis e direitos na Justiça do Trabalho, entre o regime democrático e ditatorial militar no Brasil (1953-1978). Estudos Ibero-Americanos, Porto Alegre: Vol. 42, n. 2, maio/agosto de 2016 , p. 509. Disponível em http://revistaseletronicas.pucrs.br/ojs/index.php/iberoamericana/article/view/22494 [Acesso em 10/04/2018].

${ }^{6}$ VIANNA, Luiz Werneck. Liberalismo e sindicato no Brasil. Rio de Janeiro: Paz e Terra, 1976, p. 31. 


\title{
A greve dos marítimos de junho de 1953: crise do peleguismo, libertação dos sindicatos e a matriz historiográfica do novo trabalhismo
}

Iniciado logo após a greve dos 300 mil, o movimento dos "trabalhadores do mar" incorporou e radicalizou muitas de suas práticas, contribuindo para montar o acervo das relações sindicatosempresários-governos na República de 1946. Como vimos, o corporativismo, materializado na Consolidação das Leis Trabalhistas (CLT), na unicidade sindical, no imposto compulsório, nos institutos previdenciários e na Justiça do Trabalho, seria uma peça de difícil estocagem, mesmo que os próprios sindicalistas o tenham muitas vezes ostentado. ${ }^{7}$ No que toca, porém, o caso dos marítimos em greve, o cerne da questão esteve na substituição das lideranças pelegas, que agiam para evitar o conflito de interesses antagônicos, favorecendo a "paz social" e o incontornável controle do patronato sobre as exigências de seus empregados. A greve de junho impôs novos atores políticos, substituindo aqueles que operavam a favor do Estado dentro dos sindicatos. A saída dos pelegos foi chamada de "libertação", nome bastante conhecido pela opinião pública da época, pois foi usado também para tratar da retirada dos nazistas de territórios do leste europeu, durante o término da Segunda Guerra Mundial.

A saída dos pelegos favorecia demandas que previam derrubar as más condições de trabalho em que viviam, sobretudo, os operários navais. Desse modo, tornou-se emblemática a eleição e posse da nova diretoria do Sindicato dos Operários Navais do Rio de Janeiro (SONRJ), após a greve dos marítimos, permitindo a entrada de uma liderança próxima ao Partido Comunista do Brasil (PCB), presidida por Irineu José de Souza. No entanto, é necessário afirmar que a incômoda presença dos pelegos começou a ser questionada antes mesmo da greve dos 300 mil. A esse respeito declarou o próprio Irineu José de Souza, em entrevista aos pesquisadores do Laboratório de História Oral e Iconografia da Universidade Federal Fluminense (LABHOI/UFF):

\begin{abstract}
Na época, o presidente do sindicato era o Osvaldo Garcez, um servidor da Companhia Costeira. Mas ele não queria seguir o que a classe propunha. Então, quando foi uma tarde de 1952 mais ou menos, talvez porque eu já estivesse liderando alguma coisa lá no Lóide, eu fui trazido aqui por um grupo de companheiros para tirar o pelego do cargo. Ele foi tirado assim. Afastamos ele e eu fiquei dominando o sindicato. Sem ainda estar eleito, sem nada. Os companheiros me colocaram aqui por conta deles. ${ }^{8}$
\end{abstract}

O caso narrado por Irineu José de Souza dá conta da sua entrada extralegal na presidência do SONRJ, antes da greve de 1953, quando seria oficializada essa situação. Deve-se frisar, então, que a crise do peleguismo antecede a chegada de João Goulart no Ministério do Trabalho, sendo este, na condição de ministro, quem acabou legalizando o que já vinha ocorrendo por iniciativa própria dos trabalhadores. Perante esse quadro, se poderia perguntar: seria o estilo Jango (ou a forma janguista de negociação com os trabalhadores) responsável, por si mesmo, pelas mudanças que estavam ocorrendo nos sindicatos? Como será mostrado adiante, tudo leva a crer que não. Essa percepção, no entanto, diverge da tendência historiográfica identificada com a matriz do novo trabalhismo, encontrada nas pesquisas de Ângela de Castro Gomes, Jorge Ferreira e Lucília Neves de Almeida Delgado. Para entender como se dá essa divergência será necessário rever a estrutura argumentativa desses autores.

\footnotetext{
7 GOMES, Ângela Maria de Castro. Cidadania e direitos do trabalho. Rio de Janeiro: Jorge Zahar Editor, 2002.

8 Depoimento de Irineu José de Souza. In. GOMES, Ângela Maria de Castro (Org.) A época dos operários navais. Niterói: Laboratório de História Oral e Imagem - LABHOI, 1999. Disponível em

http://www.labhoi.uff.br/sites/default/files/a epoca dos operarios navais angela de castro gomes.pdf [Acesso em 19/04/2018], p. 47.
} 
A historiadora Ângela de Castro Gomes escreveu dois importantes trabalhos sobre a passagem de João Goulart pelo Ministério do Trabalho. O primeiro deles, intitulado Getulismo e trabalhismo: tensões e dimensões do Partido Trabalhista Brasileiro (1987), foi escrito em parceria com Maria Celina Soares D`Araújo. Embora o texto não se limitasse ao período ministerial de Jango, tendo estudado as relações entre getulismo e trabalhismo após a queda do Estado Novo, este tratou de um ponto crucial para o entendimento dessa fase. Nele, as pesquisadoras do Centro de Pesquisa e Documentação de História Contemporânea do Brasil da Fundação Getúlio Vargas (CPDOC-FGV) abordaram o que seria o estilo do ministro na administração dos conflitos trabalhistas, definindo-o como mais informal e mais liberal no trato com as lideranças sindicais, afirmando, pela primeira vez, a existência do estilo Jango.

Segundo as autoras supracitadas, Jango não sabia apenas falar para os trabalhadores, mas ouvilos também. Participando de um governo em crise, Goulart teve como missão reverter a impopularidade das políticas getulistas para o mundo do trabalho. As autoras procuraram mostrar que o jovem político gaúcho, natural da mesma cidade de origem de Getúlio Vargas, procurou cumprir esta missão derrubando as formas mais explícitas de controle sobre a classe trabalhadora.

O estilo Jango viria novamente à tona no capítulo redigido por Ângela de Castro Gomes para a coletânea motivada pela entrada do arquivo João Goulart no CPDOC/FGV. No livro João Goulart: entre a memória e a história (2006), organizado por Marieta Morais Ferreira, a historiadora inicia o seu texto fazendo referência ao período ministerial de Goulart como um "acontecimento biográfico". Cabe o destaque:

Nesse sentido, os oito meses de Ministério do Trabalho de João Goulart podem e devem ser considerados um "acontecimento biográfico", fundador da trajetória desse político, num duplo sentido. Primeiro, pelas marcas que tal experiência produziu na construção da sua imagem para si mesmo e para os seus aliados mais próximos, destacando-se os membros do seu partido, o PTB. Uma imagem de político nacionalista e reformista, que estava disposto a pagar um alto preço para se posicionar ao lado dos trabalhadores - urbanos e rurais - ou, em suas próprias palavras, para sustentar uma postura de "fidelidade à sua consciência". Segundo, pelos desdobramentos que essa imagem provocou na movimentação de seus opositores no fragmento, os "entreguistas, golpistas e poderosos" - e que, desde de 1954, podiam ser facilmente identificados como integrando um grupo de políticos civis, particularmente da União Democrática Nacional (UDN), de expressivos setores militares e de fortes grupos empresariais. ${ }^{\text {? }}$

Considerando Goulart um político fiel à sua própria consciência, conforme ele mesmo a descrevia, Ângela de Castro Gomes o entende como um autêntico representante do nacional-reformismo, principal bandeira das lutas políticas da esquerda brasileira até o golpe de 1964. O período ministerial de Jango serve, segundo ela, para mostrar o quanto o político trabalhista teria sido mais do que um ministro do Trabalho, para se projetar como ministro dos trabalhadores. Na construção dessa imagem, a presença de Goulart nas negociações pertinentes à greve dos marítimos, evento que coincide com a sua entrada no MTIC, possui uma relevância especial, sendo tratada com destaque no texto. Recorrendo a documentos guardados por João Goulart e ao depoimento do seu principal assessor administrativo, Hugo de Faria, a historiadora mostra que os dez dias em que Jango se dedicou exclusivamente à negociação com os marítimos serviram como um laboratório para introduzir as práticas adequadas a um estilo mais informal de se conversar com os trabalhadores. Dentro desse contexto, ela ressalta a importância do acordo assinado em 26 de junho de 1953, nas dependências do Ministério do Trabalho, tratando-o como resultado da habilidade do ministro para aumentar a sua popularidade, atestada em uma enquete

9 GOMES, Ângela Maria de Castro. Memórias em disputa: Jango, ministro do Trabalho ou dos trabalhadores? In. Ferreira, Marieta Morais. João Goulart. entre a memória e a história Rio de Janeiro, Fundação Getúlio Vargas, 2006, p. 32. 
produzida pelos "agentes de informação" ministeriais, guardada no arquivo Jango. Os resultados dessa enquete são enfáticos em dizer que as "respostas eram unânimes, sendo o novo ministro recebido "com alegria e a certeza de que iria compreender" as justas demandas dos trabalhadores". ${ }^{10}$ O que a levou à seguinte interpretação:

(...) o que a atuação de Jango evidencia e a documentação atesta é que, desde antes de assumir o ministério, sua posição foi a de um mediador entre os sindicatos e o governo. Seu poder derivava de uma autorização pessoal de Vargas, uma vez que era o presidente de um partido político, o PTB, e não membro do staff governamental. A greve dos marítimos foi, portanto, uma espécie de prova de fogo, tanto para o ministro, quanto para uma nova estratégia política de lidar com a questão do custo de vida e das reivindicações de lideranças sindicais, mesmo as que não ocupavam cargos de diretoria. ${ }^{11}$

Embora a pesquisa da historiadora se estenda sobre todo o período em que Goulart esteve na direção do MTIC, o retorno dos marítimos à greve, em outubro de 1953, não é lembrado por ela. Talvez porque essa seja uma lembrança incômoda frente às suas conclusões de que Jango optara, única e exclusivamente, pela trilha de uma "política de tolerância" com os trabalhadores. ${ }^{12}$ Tratando da saída do ministro, logo após o expressivo aumento de 100\% do salário mínimo, ela escreve:

Nas palavras do próprio Jango, em seu pedido de demissão de 22 de fevereiro de 1954, "o verdadeiro sentido de minha atuação à frente do Ministério do Trabalho, Indústria e Comércio" era abrir "de par em par" as suas portas para os trabalhadores, para sentir de perto suas queixas e reivindicações, o que se anteviu como uma orientação que desagradaria "às forças da reação", fazendo-as se voltar contra ele. ${ }^{13}$

$\mathrm{Na}$ argumentação contida no capítulo sobre as memórias do período ministerial de João Goulart, o foco da pesquisadora esteve centrado no que ele teria representado enquanto um político que, aproximando-se dos trabalhadores, era capaz de intimidar as elites econômicas do país. Dentro de uma estratégia de renovação do trabalhismo, conferindo-lhe um novo sentido, que deixava para trás as formas mais tradicionais de liderança carismática, Jango abria oportunidades para os trabalhadores participarem da efetivação dos seus diretos, conclamando-os a fiscalizar a aplicação da CLT e a participar da administração dos fundos previdenciários. Para a autora, o posicionamento do ministro estaria de acordo com uma filosofia política que apostava na capacidade de organização das classes populares, dentro da legalidade, contida em ações, tais como o fim das intervenções nos sindicatos e a suspensão, na prática, da exigência do atestado de ideologia. A lacuna deixada em relação à continuidade da greve dos marítimos, em outubro de 1953, serve para reforçar a hipótese de que o ministério Jango teria representado uma transição retilínea do varguismo para o trabalhismo organicamente vinculado ao campo da esquerda.

No livro O Imaginário Trabalhista (2005) o professor da Universidade Federal Fluminense (UFF), Jorge Ferreira, reuniu várias pesquisas integradas ao tema. No capítulo intitulado "O ministro que conversava", o estilo Jango volta à discussão e é contrastado, mais uma vez, com o velho modo de tratar os trabalhadores, ainda vigente na gestão Segadas Vianna. É o que se lê abaixo:

Não demoraria muito para Goulart entrar em rota de colisão com Vianna, criticandoo publicamente por recorrer a métodos repressivos para conter a onda reivindicatória

\footnotetext{
10 Idem, pp. 42-43.

11 Ibidem, p. 43.

12 Ibidem, p. 43.

13 Ibidem, p. 46.
} 
do movimento sindical, em particular no caso dos marítimos. Vargas, em atitude ousada, para recuperar o seu prestígio entre os trabalhadores, desautorizou seu próprio ministro, obrigando-o a se demitir e nomeou Goulart para o Ministério do Trabalho, exatamente um ano após ascender à presidência do PTB. ${ }^{14}$

O autor destaca que o jovem ministro do Trabalho valorizava, em primeiro lugar, a proximidade e o diálogo a qualquer tempo e circunstância com os representantes sindicais, deixando de lado a repressão física e ideológica. Seria ele o responsável pela abolição, na prática, do atestado de ideologia, documento exigido aos sindicalistas para exercerem as suas atividades; assim como das intervenções nos sindicatos, mesmo se isso os fizesse mais próximos da influência comunista. Não é difícil notar a coincidência da maior parte dos exemplos e argumentos de Jorge Ferreira e Ângela de Castro Gomes, levando-os a se posicionarem em uma mesma matriz interpretativa, que chamamos de historiografia do novo trabalhismo. Ambos irão destacar o pânico provocado nas elites econômicas pela ação de Goulart no Ministério do Trabalho, especialmente a forma pela qual ele abria as portas da política e da administração pública para um novo conjunto de lideranças populares. Essas medidas anticontencionistas seriam importantes para mudar a correlação de forças no meio sindical, possibilitando a largada de uma frente de esquerda. Entretanto, cabe perguntar se elas representariam a totalidade das ações do ministro na conjuntura aqui estudada?

O principal recurso de Jorge Ferreira para interpretar a passagem de Goulart pelo MTIC não está na análise política stricto sensu. $\mathrm{O}$ autor se apoia em uma história cultural do político, desenvolvida em torno de conceitos como "imaginário" e "mitologias", para dar conta do pertencimento de Jango a uma geração que, lidando com a herança getulista, procurou oferecer ao trabalhismo um perfil ideológico mais consistente. Desta forma, ele ressalta que:

Recorrendo ao diálogo e à conciliação, mas igualmente a métodos centralizadores e instituindo a intolerância para conter os insatisfeitos com sua liderança na presidência do PTB, Goulart protagonizou um período de transição na história do trabalhismo brasileiro. ${ }^{15}$

É na perspectiva de traçar a história do período ministerial de Goulart dentro de uma história mais ampla do PTB que se encontram as pesquisas de Jorge Ferreira e Ângela de Castro Gomes, nela incluindo a atuação e a resposta obtida por Jango nas negociações relativas à greve dos marítimos. A perspectiva de ambos os historiadores não coloca os trabalhadores no centro de suas pesquisas. Seus trabalhos visam discutir a projeção e o sucesso da nova política trabalhista entre as classes populares.

O período ministerial de Jango foi também objeto de estudo da tese de Lucília Delgado, publicada em livro com o título PTB: Do getulismo ao reformismo (1989). Esta pesquisa no campo da ciência política procurou mostrar a história desse partido político de maneira plural, destacando as suas diversas linhagens e, sobretudo, o processo que levou do getulismo ao reformismo. É nesse ponto de mutação que se situa a passagem de Goulart pelo MTIC, conferindo-lhe assim um lugar de destaque dentro da obra. A autora defende que o ministro do Trabalho de Getúlio Vargas revitalizou o Partido Trabalhista, dando a largada para uma atitude reformista, que deixaria para trás os velhos ditames do getulismo. Daí em diante, os trabalhistas apostaram em uma maior concessão de direitos para os trabalhadores organizados, dialogando com os seus mais diversos representantes, inclusive comunistas. Nesse contexto, a greve dos marítimos é colocada como um evento que explicitou as divergências entre Vargas e o então ministro Segadas Vianna, obrigando-o a uma mudança de rumos.

14 FERREIRA, Jorge. O imaginário trabalhista. Getulismo, PTB e cultura política popular, 1945-1964. Rio de Janeiro: Civilização Brasileira, 2005, p. 103.

15 Idem, p. 121. 
A greve de junho entra na obra de Lucília Delgado como exemplo da implantação de uma nova política trabalhista, disposta a negociar direitos e vantagens para os trabalhadores. Ela ressalta, porém, que essa mesma política também procurou cooptar as lideranças disponíveis e neutralizar aquelas mais radicais. Em suas palavras:

Se analisarmos a gestão Goulart da perspectiva governamental, chegaremos à conclusão que o agir administrativo-político do novo ministro inseriu-se numa dinâmica na qual questões de variada ordem se conjugaram em um processo que procurava criar condições favoráveis para manutenção do poder nas mãos do Presidente Vargas. No contexto do segundo governo de Getúlio Vargas, voltava a ser usada a mesma tática, em busca da manutenção e do controle do poder político, que havia sido acionada no contexto de queda do Estado Novo: posições relativamente "avançadas" foram assumidas, procurando manter a continuidade de pequenas transformações e concessões. Nessa dinâmica, a concessão de vantagens e benefícios era uma tática que não poderia ser desprezada, pois seu poder de cooptação e neutralização de "ações radicais" era real. Em consonância com essa linha, logo que assumiu o ministério, negociou com os marítimos em greve, atendendo a maior parte de suas negociações. ${ }^{16}$

Apropriando-se do conceito de "populismo" como chave explicativa para desvendar a ação política do segundo governo Vargas, Lucília Delgado utiliza-o para ressaltar o caráter ambíguo da administração janguista. A autora, embora também possa ser incluída na matriz historiográfica do novo trabalhismo, avalia o estilo Jango de um modo mais rigoroso, com base nas vertentes da mobilização e do controle, mostrando uma forte combinação entre as duas. É deste modo que ela escreve, ainda que em poucas linhas, sobre a greve de outubro, afirmando que para contê-la "Goulart não hesitou em acionar os esquemas de controle e coerção da sua pasta: a intervenção e a repressão". ${ }^{17}$

Concluindo esta seção, devemos lembrar que a atuação de João Goulart no Ministério do Trabalho não deixou de estar pautada naquilo que Maria Celina Soares D`Araújo (1982) chamou, na tentativa de definir a ação política do segundo varguismo, de estratégia do "consenso máximo". ${ }^{18} \mathrm{O}$ que queremos dizer com isso é que o ministro procurou satisfazer ambas as partes do conflito trabalhista, dentro de um expediente que jogou muitas vezes com a expectativa da obtenção de direitos, garantias e vantagens para os assalariados, nem sempre efetivadas e cumpridas, mesmo depois de acordadas. Exemplo mais do que suficiente dessa prática se encontra no acordo que fechou o primeiro tempo da greve dos marítimos. Nos meios políticos trabalhistas, este foi visto como um sucesso inquestionável, divulgado intensivamente para o público mais amplo por meio da principal mídia impressa governista, o jornal Última Hora. Entre os marítimos, porém, a sua aceitação seria muito mais reticente, conforme se pode observar na pesquisa do seu jornal de classe.

\section{O Jango de Orla Marítima}

O jornal Orla Marítima foi um periódico que representou os trabalhadores marítimos, sendo, porém, organizado pelo segmento dos capitães de náutica. Esses trabalhadores eram os melhor remunerados e os mais escolarizados dentre os marítimos. Eles também possuíam autoridade dentro das embarcações, garantindo-lhes o poder sobre o tráfego naval em toda extensão da costa brasileira. O diretor-responsável pelo jornal era o capitão Emílio Bonfante Demaria, destacado ativista da greve de

16 DELGADO, Lucília Neves. PTB: do getulismo ao reformismo. São Paulo: Marco Zero, 1989, p. 137.

17 Idem, p. 150.

18 D`ARAÚJO, Maria Celina Soares. O segundo governo Vargas (1951-1954). Democracia, partidos e crise política. Rio de Janeiro: Zahar, 1982, p. 113. 
junho, sendo Armando Zanini Filho o redator-chefe e Celso Maio o secretário-geral. Essa fonte histórica será fundamental para oferecer um contraditório à historiografia que vem se debruçando sobre o movimento dos marítimos pelo ângulo do "novo trabalhismo", mostrando a imagem de João Goulart traçada pelos trabalhadores.

A hipótese aqui defendida é a de que o papel do ministro do Trabalho, no que toca à crise do peleguismo, ou seja, o afastamento deste dos sindicatos, e o arranque da luta de classes durante o segundo governo Vargas teria sido considerado menor entre os marítimos do que imagina a historiografia dominante, ainda mais quanto à sua capacidade de mediação dos conflitos sem imposição da força. Uma leitura atenta da coleção desse periódico, depositado na Biblioteca Nacional do Rio de Janeiro, destaca a organização de classe dos trabalhadores do mar, em contraste com uma representação negativa do ministro do Trabalho.

Os pontos acima descritos indicam a distância entre as práticas sindicais em uso pelos marítimos e o modelo de "sindicalismo populista", proposto a partir dos estudos de Francisco Weffort sobre o populismo na política brasileira do período entre 1946 e 1964. Como aponta Marcelo Badaró de Mattos, esse modelo interpretativo acentua a "inconsistência organizatória" nos locais de trabalho, em detrimento das ações vinculadas à "estrutura sindical oficial", reduzindo assim, por meio de negociações "pelo alto", os "conflitos diretos entre o capital e o trabalho". ${ }^{19}$ Não é o que encontramos ao olharmos para os marítimos, uma das categorias mais antigas de trabalhadores nacionais, instalados nas docas e estaleiros da Baía de Guanabara desde os tempos coloniais, tendo passado por diversas experiências organizativas, políticas e ideológicas, envolvendo o mutualismo, o anarco-sindicalismo e o comunismo. ${ }^{20}$ No decorrer do tempo, eles acumularam e solidificaram formas de solidariedade de classe que nos permitem dizer que dificilmente poderiam estar sendo inventados. As exigências feitas no "Memorial dos 25 itens", entregue para João Goulart em junho de 1953, demonstram uma visão aguda sobre os problemas quotidianos, tais como a melhoria da alimentação servida pelas empresas e a regulamentação do trabalho a bordo dos navios mercantes. A promoção de novos espaços organizativos de base, dentro dos locais de trabalho, nos leva a conhecer o potencial criativo desses trabalhadores, que se reuniam para discutir direitos não apenas dentro dos sindicatos, criando os conselhos de fábrica e as praças de liberdade sindical. Voltemos agora ao jornal que nos serve de referência nessa pesquisa.

Na coluna Pau Neles, de Armando Zanini Filho, publicada no primeiro número do jornal (14/08/1953), temos uma longa análise do papel de Goulart durante a greve. O título por si só demonstra a contrariedade dos marítimos em relação ao ministro: "Um terremoto abalou o país: caiu a pesadíssima máscara de Jango". O articulista acusava Goulart de agir com dubiedade em relação à escolha do novo presidente da Federação Nacional dos Marítimos (FNM), disputada por um dos expoentes da greve de junho: o comandante Emílio Bonfante Demaria. Após ter prometido a mais ampla liberdade sindical, o ministro estaria protelando as eleições naquele órgão para apoiar uma "junta peleguista". Em sua coluna, Zanini apontava a dubiedade como uma marca indelével da passagem de Jango pelo ministério.

Para o redator-chefe daquele órgão de classe, o ministro queria "aparecer ante o povo como o homem que atendeu às reivindicações dos marítimos", enquanto colocava na federação "uma junta de 'Laranjeiras-mirins', que serão mais Laranjeiras que o próprio Laranjeiras". ${ }^{21}$ Uma outra denúncia de Zanini Filho, ainda mais grave, envolvia um acordo promovido por Goulart com diversas lideranças sindicais, que assumiam "o compromisso de não medir esforços no sentido de que suas classes ajam de

19 MATTOS, Marcelo Badaró. Novos e velhos sindicalismos; Rio de Janeiro (1955/1968). Rio de Janeiro: Vício de Leitura, 1998, p. 58.

${ }^{20}$ PESSANHA, Elina. Niterói operário: o caso dos trabalhadores da indústria naval. In. Martins, Ismênia de Lima e Knauss, Paulo. Cidade múltipla: temas da história de Niterói. Niterói: Niterói Livros, 1997, p. 151.

21 ZANINI FILHO, Armando. Um terremoto abalou o país: caiu a pesadíssima máscara de Jango. Orla Marítima, 14/08/1953, p. 2. 
acordo com os interesses do ministério", ${ }^{22}$ ou seja, não partissem para uma nova greve, mesmo se os pontos anteriormente definidos com o patronato não fossem cumpridos. Era contra o surgimento de um peleguismo de novo tipo que se voltava o jornal, a ponto de pedir que o ministro renunciasse, depois da queda da sua máscara de "milhares de toneladas". Essas representações são importantes para pensarmos nas razões da eclosão de uma nova greve, pouco tempo depois do sugerido sucesso negocial de Jango. Visto dessa forma, será tão simples dizer que o ministro se movia com firmeza nas águas turvas das relações trabalhistas?

\section{O outubro dos marítimos}

O não cumprimento de pontos fundamentais do acordo firmado em 26 de junho de 1953 levou os trabalhadores da Marinha Mercante a uma nova greve geral, no mês de outubro. Esquecido pela historiografia que trata a greve dos marítimos como parte da trajetória do "novo trabalhismo", esse segundo movimento realça a visão predominante acerca de Jango entre as lideranças mais atuantes na imprensa sindical, assim como a truculência usada pelo aparato repressivo do Estado para contê-las.

Descrentes da política do Ministério do Trabalho, os editores de Orla Marítima chamavam atenção para o fato de Goulart ter atuado muito mais pelos patrões ao negociar o desfecho da primeira greve nacional dos marítimos. O sucesso da empreitada que levou os trabalhadores à mesa de negociação teria como preço inibir novas investidas no conflito de classes. É o que depreendemos, mais uma vez, da consulta à coluna assinada por Armando Zanini Filho. Nela, o articulista expôs da seguinte forma o pensamento da classe empresarial, e de seus representantes na esfera do governo, em relação à greve de junho:

Durante a greve diziam nossos inimigos (Paulo Ferraz, Issac Cunha, Hugo de Faria, Waldemar Motta e companhia) com ares tristes:

- Vocês conseguiram uma união extraordinária e uma greve sem precedentes...

E depois - enquanto uma sensação de sádico êxtase dominava todo o corpo acrescentavam:

- Porém, jamais conseguirão fazer outra igual 23

A polêmica encontrada em Orla Marítima nos leva a pensar se Jango conseguiu, de fato, convencer o pessoal da marinha mercante do seu papel na luta contra os pelegos, pela libertação dos sindicatos e pela entrada dos trabalhadores em uma era de reconhecimento público de suas demandas e reivindicações. A denúncia sobre a queda da sua "pesadíssima máscara" é uma representação mais do que clara do quanto havia de resistência dos setores mais organizados dos trabalhadores do mar. Essa representação ganha mais expressividade quando acrescida da leitura do novo Manifesto do comando nacional de greve, publicado na folha marítima em 01/10/1953. Nele se questiona o papel do Ministério do Trabalho nas articulações jurídico-políticas que permitiam a sobrevivência do renegado João Batista de Almeida, vulgo Laranjeiras, na diretoria da Federação Nacional dos Marítimos, em uma das suas "mais abjetas manobras". 24

Esse seria apenas um dos aspectos, embora dos mais significativos, da percepção dos marítimos e suas classes anexas quanto ao desrespeito com o qual o governo trabalhista os vinha tratando. A necessidade de uma nova greve, porém, seria fruto principalmente do não cumprimento das cláusulas

\footnotetext{
22 Idem. O acordo foi publicado também nessa edição, sob o título de "documento degradante". Entre os que o assinaram estiveram os presidentes dos sindicatos dos oficiais de máquinas, foguistas, taifeiros, carpinteiros navais, comissários, radiotelegrafistas, marinheiros, conferentes, motoristas e condutores, empregados de escritório, práticos e mestres de cabotagem. Era com essas lideranças que Goulart pretendia desenvolver um sindicalismo "sadio", capaz de medir forças com os comunistas. 23 ZANINI FILHO, Armando. Voltaremos à greve. Orla Maritima, 01/10/1953, p. 3.

${ }^{24}$ Novo manifesto do comando de greve. Orla Marítima, 01/10/1953, p. 11.
} 
encontradas no acordo anterior, assinado em 26 de junho de 1953. É o que fica exposto na matéria que compõe a manchete de capa do jornal Orla Marítima, publicada na véspera do retorno dos marítimos à greve:

\begin{abstract}
Há quatro meses, portanto, que esperamos pacientemente pelos pagamentos acordados e que nos são devidos alguns desde quinze de novembro de 1948, por força de lei e decisão judicial.

Durante todo esse tempo o ministro do Trabalho vem distribuindo notas oficiais, pela imprensa falada e escrita, declarando que todas as reivindicações dos marítimos foram atendidas! Mas que lidas atentamente revelam a mentira.

Destarte, concluímos que tais notas destinam-se a confundir a opinião pública que na última greve solidarizou-se com a causa dos marítimos, por ser justa; pois que aos marítimos não enganam tais notas, simplesmente porque ao receberem seus envelopes de pagamento mensal, nele não encontram todo o dinheiro a que tem direito. ${ }^{25}$
\end{abstract}

Os marítimos procuravam mostrar que havia uma distância entre a propaganda e a realidade das ações ministeriais. A fama do ministro negociador não parece, desse ponto de vista, ter chegado ao público por ele representado. A prisão de vários representantes dos marítimos, inclusive participantes do jornal aqui estudado, como é o caso de Arnaldo Zanini Filho, preso no início de outubro, mostra o uso do braço repressivo do Estado, em sintonia com os interesses empresariais. Além disso, encontramos nas páginas de Orla Marírtima reportagens sobre a repressão das formas organizativas dos locais de trabalho que brotaram da greve de junho, como a prisão do operário naval Degenildo da Silva Pinto, responsável pela criação de um conselho de fábrica no Dique Lahmeyer. Segundo Barsted, no único estudo que se aprofunda nos acontecimentos de outubro de 1953, no momento em que a nova paralisação por tempo indeterminado foi decidida, o Sindicato dos Marinheiros, local da assembleia que deflagrou o movimento, foi invadido por policiais e fuzileiros navais, que agiram violentamente, prendendo e espancando diversas pessoas. ${ }^{26}$ Essas e outras situações nos mostram a relevância do uso da imprensa sindical e popular como fonte histórica para se compreender melhor esse período, em que as novas lideranças trabalhistas levantaram alternativas políticas nacional-populares, muitas vezes à revelia dos seus próprios representados.

Em uma outra mídia impressa consultada, o jornal Imprensa Popular, encontramos críticas ainda mais pesadas ao ministro João Goulart. O jornal publicado pelo PCB na cidade do Rio de Janeiro levantou o aspecto fascista da nova política trabalhista de Vargas. A ação extremamente repressiva do governo Vargas em relação à greve de outubro de 1953, foi completamente diferente da sua ação conciliadora, negociada por Jango na greve de junho do mesmo ano. O estilo Jango parece ter sucumbido aos projetos de Vargas. A proposta de negociar com os trabalhadores não prevaleceu nesta segunda greve de 1953. A severa repressão sobre estes grevistas, bem como a denúncia de que este governo era uma farsa no que se refere ao diálogo com a classe trabalhadora aponta muito mais do que um acordo pacífico. As falas dos operários navais, registradas nesse jornal, no dia 21 de outubro de 1953, na matéria intitulada "Trama fascista de Vargas e Jango", apontam para a violência impetrada contra os grevistas, bem como denunciam a farsa que seria o diálogo do governo com a classe trabalhadora. O que mais surpreende neste registro jornalístico é a denúncia das práticas de tortura dentro de navios de guerra da Marinha. Operários navais teriam sido carregados para o interior dessas embarcações, onde passaram dias sendo torturados. Jango desta vez não se dedicou, como em junho, a negociar junto aos grevistas, pelo contrário, estava licenciado do cargo, viajando pelos estados do norte e nordeste.

A violenta reação estatal contra o segundo tempo da greve dos marítimos, à exceção da dissertação de Denis Barsted, publicada em 1981, vem sendo terminantemente esquecida pela histografia,

25 Motivo da nova greve geral dos marítimos! Orla Marítima, 15/10/1953, p. 1.

26 BARSTED, Op. Cit., p. 165-166. 
sobretudo a que trata desse período pelo viés da história política. Por que essa historiografia prefere silenciar diante disso? O retorno à repressão policial, após um breve intervalo em que o estilo Jango entrou em cena, contraria as expectativas em torno do novo trabalhismo. Sabe-se, porém, que a escolha do que deve ser silenciado e esquecido é, por si só, um ato político. O desinteresse de parte da historiografia quanto à repressão praticada no segundo governo Vargas, e o silêncio do ministro do Trabalho durante a greve dos marítimos de outubro de 1953, são sintomas da produção de um silenciamento que busca esvaziar as contradições em torno da nova política trabalhista. Os autores deste artigo, no entanto, entendem que estas contradições são um campo oportuno para a compreensão das relações entre Estado e sociedade no Brasil da metade do século XX.

\section{Bibliografia}

Barsted, Denis Linhares. Medição de forças: o movimento grevista de 1953 e a época dos operários navais. Rio de Janeiro: Zahar, 1981.

Buonicore, Augusto César. Sindicalismo vermelho: a política sindical do PCB entre 1948 e 1952. Cadernos AEL, v. 7, n. 12/13, 2000, pp. 15-44. Disponível em https://www.ifch.unicamp.br/ojs/index.php/ael/article/view/2485 [Acesso em 04/04/2018].

Corrêa, Larissa Rosa. O corporativismo dos trabalhadores: leis e direitos na Justiça do Trabalho, entre o regime democrático e ditatorial militar no Brasil (1953-1978). Estudos Ibero-Americanos. Porto Alegre: Vol. 42, n. 2, p. 500-526, maio/agosto de 2016. Disponível em

http://revistaseletronicas.pucrs.br/ojs/index.php/iberoamericana/article/view/22494 [Acesso em 10/04/2018].

D’Araújo, Maria Celina Soares. O segundo governo Vargas (1951-1954). Democracia, partidos e crise política. Rio de Janeiro: Zahar, 1982.

Delgado, Lucília Neves. PTB: do getulismo ao reformismo. São Paulo: Marco Zero, 1989.

Ferreira, Jorge. O imaginário trabalhista. Getulismo, PTB e cultura política popular, 1945-1964. Rio de Janeiro: Civilização Brasileira, 2005.

Gomes, Ângela Maria de Castro e D`Araújo, Maria Celina Soares. Getulismo e trabalhismo: tensões e dimensões do Partido Trabalhista Brasileiro. Rio de Janeiro: Fundação Getúlio Vargas, 1987.

. (Org.) A época dos operários navais. Niterói: Laboratório de História Oral e Imagem -

LABHOI, 1999. Disponível em

http://www.labhoi.uff.br/sites/default/files/a epoca dos operarios navais angela de castro gomes.pdf

[Acesso em 19/04/2018].

Cidadania e direitos do trabalho. Rio de Janeiro: Jorge Zahar Editor, 2002.

. Memórias em disputa: Jango, ministro do Trabalho ou dos trabalhadores? In. Ferreira, Marieta Morais. João Goulart. entre a memória e a história Rio de Janeiro, Fundação Getúlio Vargas, 2006.

Pessanha, Elina. Niterói operário: o caso dos trabalhadores da indústria naval. In. Martins, Ismênia de Lima e Knauss, Paulo. Cidade múltipla: temas da história de Niterói. Niterói: Niterói Livros, 1997, pp. 131-168.

Stotz, Eduardo Navarro. Nacionalismo, intervencionismo estatal e expansão do movimento operário (19501955). In. Lobo, Eulália Lahmeyer (Coord.) Rio de Janeiro operário: natureza do Estado, condições de vida e consciência de classe. Rio de Janeiro: Acess Editora, 1992, pp. 222-265.

Telles, Jover. O movimento sindical no Brasil. São Paulo: LECH, 1981.

Vianna, Luiz Werneck. Liberalismo e sindicato no Brasil. Rio de Janeiro: Paz e Terra, 1976.

\section{Fontes}

Coleção do jornal Orla Marítima, seção de Periódicos da Biblioteca Nacional do Rio de Janeiro.

Coleção do jornal Imprensa Popular, seção de Periódicos da Biblioteca Nacional do Rio de Janeiro. Disponível em http://bndigital.bn.br/acervo-digital/imprensa-popular/108081

[Acesso em 20/03/2019]. 